\title{
Transmission Routes and Infection Control of Novel Coronavirus-2019 in Dental Clinics - A Review
}

\author{
Sana Ali $^{1}$, Uroosa Zeb ${ }^{1}$, Mashooq Khan ${ }^{2}$, Anees Muhammad ${ }^{1}$ \\ ${ }^{1}$ College of Medical Technology, Bacha Khan Medical College, Mardan \\ ${ }^{2}$ Institute of Paramedical Sciences, Khyber Medical University, Peshawar
}

\begin{abstract}
A B S TR ACT
The novel Coronavirus (2019-nCoV) pandemic began in Wuhan, China with Severe Acute Respiratory Syndrome (SARS) in December, 2019. The virus transmitted from China to other countries by traveling of the infected individuals. The number of infected populations with Coronavirus is increasing day by day with an increased mortality rate. The signs and symptoms of the disease include fever, non-productive cough, dyspnea, and fatigue. The transmission routes of the virus include respiratory secretions or droplet infection and direct contact with the infected person. Dentists are a group of professionals that are highly exposed to infectious diseases. The nCoV-19 is transmitted from patient to dentist and dentist to patient mainly through aerosol and splatter produced by the dental procedure and saliva of an infected person. To avoid transmission of the virus from patient to dentist and from dentist to other $p$ atients, screening tests should be done at dental setups. The use of gloves, face shields, masks, gowns, and antiseptic handwash are mandatory for the dentist. Awareness programs should be conducted to prevent further transmission of the disease. We searched Google, Google Scholar, WHO website for coronavirus and National Institute of Health website (nih.org.pk) for relevant literature by using various MeSH terms including '2019-nCoV', 'transmission of 2019nCoV in dental clinics', 'dentistry and COVID-19' and 'infection control', etc

Key words: COVID-19, Dental clinics, Infection control, Transmission
\end{abstract}

Authors' Contribution: Correspondence:

1,2Conception; Literature search; Manuscript Anees Muhammad

design and drafting; Critical analysis and Email:aneesafridi15295@yahoo.com Manuscript review; Manuscript editing.

Cite this article. Ali S, Zeb U, Muhammad A. Transmission Routes and Infection Control of Novel Coronavirus-2019 in Dental Clinics - A Review. J Islamabad Med Dental Coll.2020; 9(1):65-72. Doi: 10.35787/jimdc.v9i1.517

\section{Introduction}

Coronaviruses are a group of RNA viruses, singlestranded and enveloped, that can infect animals as well as human beings. ${ }^{1}$ The four genera of Coronavirus are alpha, beta, gamma, and delta. Six Coronaviruses are recognized to infect human beings, with four from the alpha type of Coronavirus and two from a beta type of Coronavirus. The alpha Coronavirus can cause mild upper respiratory illness that is "common cold" while the beta type leads to severe and serious illness. ${ }^{1,2}$

The SARS-CoV (Severe Acute Respiratory Syndrome-Coronavirus) was reported between 2002-2003 in China, with infection in 8,098 and death in 774 affected individuals. The actual cause of the syndrome remained unclear but bats were considered to be the origin of this virus that 
transmitted to other mammals. After 2004, not even a single case of SARS-CoV was reported. ${ }^{1}$

The Middle East Respiratory Syndrome Coronavirus (MERS-CoV) emerged in Saudi Arabia in the year 2012. ${ }^{1,3-5}$ These cases of viral infection occurred at irregular intervals. The origin of the MERS-CoV is the same as SARS-CoV with infection in bats transmitted into camels with further transmission to humans. ${ }^{1,6,7}$ These viruses spread through air by sneezing or coughing of the infected person as well as by bodily contact (i.e. handshaking etc.) with the infected person. Thus the transmission was airborne as well as through direct contact with the patient and the object that was contaminated with the virus. ${ }^{8}$ Since 2012 , about 2,494 cases have been reported by the World Health Organization (WHO) with 858 deaths and a mortality rate of $35 \% .{ }^{1}$ More cases emerged from Saudi Arabia followed by the United Arab Emirates. ${ }^{8}$ Awareness of the population and dental professionals regarding the spread of the disease is important. ${ }^{9}$

Dentists might play a role in the spread of the infection because their work primarily involves the oral cavity and hence contact with saliva of different patients. Some of the dentists do not use proper personnel protective equipment (gloves, gown, goggles, masks, hair and foot covers) during routine procedures, which is one of the possible way of transmitting various viral and bacterial infections. Moreover, aerosol and splatter are produced during various dental procedures like scaling, polishing, cavity preparation and tooth cutting. These aerosol and splatter are mixed with oral fluids (i.e. saliva) of the patient, which become air borne with the use of rotary hand pieces and thus can transmit the COVID-19 disease to the dentists. ${ }^{9}$

This review article highlights possible high-risk transmission of the virus in dental clinics in the current pandemic of 2019-nCoV. The main purpose is to increase awareness and prevent transmission of this virus among the dentists and their patients during dental practice. We searched Google, Google Scholar, WHO website for coronavirus and National Institute of Health website (nih.org.pk) for related literature reported in English language. Different 'MeSH' terms were used, such as '2019nCoV', 'transmission of 2019-nCoV in dental clinics', 'dentistry and 2019-nCoV', 'current status of 2019nCoV' and 'infection control', etc. Articles related to previous pandemics due to Coronavirus, current pandemic of 2019-nCoV and dentistry were included. Hence all relevant articles published in various international journals, government reports, World Health Organization reports, National Institute of Health (Pakistan) reports about 2019nCoV from December, 2019 to March, 2020 were retrieved. Literature pertaining to previous epidemics and pandemics due to influenza and coronavirus was also included to give a historical perspective.

\section{Recent Outbreak of COVID-19}

In the early days of December 2019, the WHO office in China received reports of some cases of pneumonia having an unknown cause. The cases emerged in Wuhan which is a city of Hubei province in China. After a few weeks, the agent responsible for the disease was declared to belong to the family of Coronavirus and hence named as 2019 novel Coronavirus (2019-nCoV). The 2019-nCoV is currently named as SARS-CoV-2 and the disease caused by the virus as COVID-19 has spread from Wuhan (China) to several other countries with a variable number of cases and different rates of transmission. ${ }^{10,11}$

\section{Prevalence of COVID-19}

About 1,67,515 individuals have been infected with nCoV-19 throughout the world with 6,606 deaths till March 16, 2020. The occurrence ratio is going to double every 6.4 days. Till March 16, 2020 the number of cases in China reached up to 81,077 
with 3,218 deaths. The total affected countries in the world are 150 in number. Besides China, outbreak has also occurred in Italy, Iran, Republic of Korea, Spain and France. The number of cases is abruptly increasing in Italy with a high mortality rate of approximately $7.3 \%$, the highest in the current outbreak. ${ }^{12}$ In Pakistan, a total of 887 confirmed cases were detected in different regions, with 6 causalities reported till March 23, 2020. Majority cases have been identified from Sindh (Karachi), followed by Baluchistan, Federal capital Islamabad, Gilgit Baltistan, Punjab, Khyber Pakhtunkhwa, Merged Areas (Ex-Fata), Azad Jammu and Kashmir, respectively. ${ }^{13}$ It is estimated that cases in Pakistan are imported from different countries especially pilgrims travelling from border city of Taftan, Iran.

\section{Mode of Transmission}

The nCoV-19 is believed to be transmitted primarily through respiratory secretions and also from person to person contact. This virus is seen in the saliva of infected patients which means it can be transmitted through oral fluids of the infected person to others, ${ }^{14}$ through sneezing, coughing or talking. The airborne particles when inhaled have a high risk of transmission from one person to another. ${ }^{14,15}$ Thus contact transmission, droplet transmission, and person to person transmission are different modes of transmission of 2019nCov. ${ }^{16}$

The sources for the airborne contamination in dentistry are dental instruments, saliva, respiratory sources and the operative site. ${ }^{17}$

\section{Saliva and Respiratory sources of contamination}

Saliva continuously makes the oral environment wet. The fluid in the oral cavity is mostly contaminated with different pathogens including many types of bacteria and viruses. The plaque or calculus present on the tooth surface is the major source of these microorganisms, either supragingival or subgingival. Apart from these, the oral cavity also serves to protect the nose, throat and respiratory system from entry of these pathogenic bacteria and viruses. Dental procedures of any type that can aerosolize this saliva will lead to airborne contamination with organisms from any or all of these sources.

The commonly present bacterium that has a serious threat to the dentist is mycobacterium tuberculosis which leads to TB and blood-borne viral diseases like Hepatitis B, Hepatitis C and HIV. The saliva and nasopharyngeal secretions also contain other pathogens and viruses like influenza, herpes virus, and the SARS virus. Airborne disease $s$ have the ability to transmit to the dentist through dental procedures that produce aerosol and splatter. ${ }^{17}$

\section{Signs and Symptoms of COVID-19}

A person infected with 2019-nCoV will manifest lower respiratory tract illness, for example, dry cough (in $67-82 \%$ cases), shortness of breath that is dyspnea (in 38\%), fever (in 83-99\% of cases), kidney failure and eventually death. ${ }^{1,11,14}$

The least common features are headache, nausea, vomiting, diarrhea, nasal congestion and sore throat. ${ }^{16}$ An elevation of AST, LDH, D-dimer, and prolonged prothrombin time support the diagnosis of viral infection. Findings of pneumonia through $X$ rays or CT scans will be seen in all the 2019-nCoV patients. ${ }^{1}$

\section{Diagnosis and Treatment of COVID-19}

The 2019-nCoV can be diagnosed with the help of Reverse-transcription Polymerase Chain Reaction (RT-PCR). The suspected person has to be analyzed through RT-PCR of upper respiratory (nasal and pharyngeal swabs) or lower respiratory specimens (sputum, bronchoalveolar lavage, tracheal aspirate or bronchoscopic brush biopsy). ${ }^{18}$ The specimen of 
blood and feces may also be utilized for the analysis of 2019-nCoV through RT-PCR. RT-PCR is the only available diagnostic procedure throughout the world. No serological or immunochromatography commonly used to treat Human Immune Deficiency Virus, for example, ritonavir-boosted lopinavir, are going to be assessed for

\begin{tabular}{|c|c|c|c|c|c|c|}
\hline Year & Type of Virus & Disease & $\begin{array}{l}\text { Place of } \\
\text { Origin }\end{array}$ & $\begin{array}{l}\text { Important Characteristics of } \\
\text { Virus }\end{array}$ & $\begin{array}{l}\text { Epidemic/ } \\
\text { Pandemic }\end{array}$ & References \\
\hline 1918 & H1N1 & $\begin{array}{l}\text { Influenza (Spanish } \\
\text { flu) }\end{array}$ & US & $\begin{array}{c}\text { 20-50 million deaths, Lethal in } \\
\text { young adults }\end{array}$ & Pandemic & 19 \\
\hline 1957 & $\mathrm{H} 2 \mathrm{~N} 2$ & Influenza (Asian flu) & China & $\begin{array}{c}2 \text { million deaths, Lethal in } \\
\text { elderly }\end{array}$ & Pandemic & 20 \\
\hline 1968 & $\mathrm{H} 3 \mathrm{~N} 2$ & $\begin{array}{c}\text { Influenza (Hong Kong } \\
\text { flu) }\end{array}$ & Hong Kong & $\begin{array}{c}1 \text { million deaths, Lethal in } \\
\text { elderly (>65 years) }\end{array}$ & Pandemic & 21 \\
\hline 1977 & H5N1 & Influenza (Bird flu) & Hong Kong & $\begin{array}{c}352 \text { deaths, Linked to poultry, } \\
\text { human-human transmission } \\
\text { rare }\end{array}$ & Pandemic & 22 \\
\hline 2002 & SARS-CoV & SARS & China & 774 deaths & Epidemic & 23 \\
\hline 2009 & H1N1 & Influenza (Swine flu) & Mexico & $\begin{array}{l}18000 \text { deaths, combination of } \\
\text { a Eurasian swine flu virus with } \\
\text { another strain (mix of bird, } \\
\text { swine and human flu virus) }\end{array}$ & Pandemic & 24,25 \\
\hline 2012 & MERS-CoV & MERS & Saudi Arabia & 700 deaths & Epidemic & 26,27 \\
\hline 2013 & $\mathrm{H} 7 \mathrm{N9}$ & Influenza (Avian flu) & China & $\begin{array}{l}295 \text { deaths, mostly affected } \\
\text { old adults } \geq 60 \text { years }\end{array}$ & Epidemic & 28 \\
\hline 2019 & nCoV-19 & COVID-19 & China & 16,565 deaths till now & Pandemic & 29 \\
\hline
\end{tabular}

technique exist for detection of 2019-nCoV. ${ }^{18}$ However, viral profile (Hepatitis etc.), hematological tests and creatine kinase may be performed for suspected or confirmed COVID-19 patients. Imaging techniques may also be helpful in diagnosis of 2019-nCoV. ${ }^{30}$

Nucleic acid amplification is also utilized to diagnose SARS-CoV through saliva and sputum. ${ }^{31,32}$ The availability of salivary tests at the dental setup also helps in the diagnosis of any infectious virus. ${ }^{32}$

The treatment of $\mathrm{nCoV}$-19 is mainly supportive with use of hydroxychloroquine and azithromycin, as option for these patients. However, some antiviral drugs (e.g. oseltamivir) that were used for treatment of the initial cases did not give beneficial effects against 2019-nCoV. In China, drugs
COVID-19 infection. It is also planned to use remdisivir as a treatment option against 2019nCoV, as it has shown high efficacy against MERSCoV and SARS-CoV in the past. The WHO and CDC do not recommend the use of corticosteroids in the treatment of 2019-nCoV infection. Vaccine for the control of 2019-nCoV is also underinvestigation. ${ }^{30}$

\section{COVID-19 and its risk for Dental Professionals}

There are many microbiological risk factors in dentistry including prions, viruses, bacteria, protozoa, and fungi. The routes may be bloodborne, saliva droplet infection and direct contact with an infected person. The droplet aerosol from an infected patient, the aerosol that comes out of the handpiece that contains 2019-nCoV and 
contaminated instruments can lead to infection in the dental professionals. ${ }^{33}$

\section{Aerosol and Splatter in Dentistry}

Micik and colleagues were the first to use the term aerosol and splatter at the time when they were working on aerobiology. The term aerosol is defined as those particles which have lesser than 50 um diameters. These are small enough to stay in the air before settling down or entering the respiratory tract. Pneumonic plague, influenza, Legionnaires' disease, and Severe Acute Respiratory Syndrome are transmitted through aerosol. On the other side, the term splatter is defined as those particles that have a diameter greater than 50um. These particles are larger in size and are unable to stay in the air. So, the greater chances of crossinfection in dentistry are through aerosol which is airborne and can enter the respiratory tract. However, splatters are also a threat to pass infection from patients to the dentist. TB is transmitted through the droplet nuclei produced during coughing or sneezing of an infected individual or from the splatter of the ongoing dental procedure. Thus splatter and droplet nuclei also transmit infectious diseases from patients to dental professionals like measles, herpes, and SARS. ${ }^{17}$

\section{Approaches to minimize the risk of COVID-19 in Dental Clinics}

The most important control measure for 2019$\mathrm{nCoV}-19$ infection is hand hygiene. As the dentist is in direct contact with the patients so he/she has to use hand sanitizers/ antiseptics before and after finishing the dental procedure. This will help in prevention of transmission of $\mathrm{nCoV}-19$ infection to the dentist as well as the patient. ${ }^{2,18,34}$

The dentist should provide oxidative mouth wash to the patient before starting the dental procedure to prevent the transmission of 2019-nCoV from the saliva of an infected patient. ${ }^{35}$ Sterilized instruments for each patient should be used and the area surrounding the patient should be disinfected before starting with the next patient.

One hand technique for recapping needle should be applied with use of sharps container for used needles and surgical blades. ${ }^{34}$

Dentists and other staff must wear personal protective equipment (PPE) like surgical gloves, $\mathrm{N}$ 95 masks, long sterilized gowns and eye protectors with face shields when performing dental procedures that produce aerosol and splatter. ${ }^{36-39}$

\section{Awareness among general population visiting Dental-Setup}

Before going to dental setups, people should have all the related information about nCoV-19. They should be aware of the cause, signs and symptoms, and safety measures of nCoV-19 infection. Seminars and workshops should be arranged for the awareness of general public regarding transmission of $\mathrm{nCoV}-19$ and their respective preventive measures. People should be asked to avoid unnecessary visits to crowded areas and medical health care and dental setups. If the visit is absolutely necessary, then use of masks should be promoted. They should avoid contact with individuals who show signs and symptoms of $\mathrm{nCoV}$ 19 or flue and cough. After the dental procedure, the patient, as well as the dentist, should wash their hands with antiseptics.

\section{Recommendations for Dentists in Current Scenario}

Dentists should be aware of the patient's recent travel history, the incubation period of the disease, isolation protocol of the dental procedure and appropriate disposal of used instruments. ${ }^{40}$

Strict preventive measures should be employed for nCoV-19 infection while working in their dental setups. Screening tests should be available at the 
dental setup and if any patient shows positive result for the virus, he should be referred to the Medical Health Facilities identified for screening and treatment. Dentists should search for latest information about 2019-nCoV infection and keep themselves updated from reliable national and international sources to better handle cases with this pandemic infection.

\section{Conclusion}

The novel Coronavirus is transmitted through direct person to person contact and respiratory droplet infection. The dental staff is at a higher risk for nCoV-19 infection as they are exposed to the aerosol and splatter produced during a dental procedure. The risk of transmission can be reduce d by taking some precautions. These include the use of antiseptic hand wash, rubber dam isolation, and mouth rinse for patient before dental procedure, gloves, protective eye wears, gowns, and masks. Moreover, it is necessary to arrange seminars and awareness programs for the dentist regarding dental practice during this outbreak. Appropriate precautionary measures can play an important role in reducing transmission and further spread of nCoV-19 infection.

\section{Acknowledgment}

We are thankful to all the staff of College of Medical Technology, especially Project Director, Dr. Abdul Jamil, Dr. Nasir Ali, Miss Areena Khan, Mr. Hidayat Khan and Muhammad Owais for their support and suggestions.

\section{References}

1. Crawford B, Kasmidi M, Korompis F, Pollnac RB. Factors influencing progress in establishing community-based marine protected areas in Indonesia. Coastal Management. 2006; 34(1): 39-64. Doi:10.1080/08920750500379300

2. Mirza MB, Bhagat TV, Inderjit MG, Aljeaidi ZA. Middle East respiratory syndrome and precautions to be taken by dental surgeons. JHS. 2016; 4(2): 105 . Doi: 10.4103/1658-600X.179821

3. Al Mohaissen M. Awareness among a Saudi Arabian university community of Middle East respiratory syndrome coronavirus following an outbreak. East Mediterr Health J. 2017; 23(5): 351-60.

4. Baseer MA, Ansari SH, AlShamrani SS, Alakras AR, Mahrous R, Alenazi AM. Awareness of droplet and airborne isolation precautions among dental health professionals during the outbreak of corona virus infection in Riyadh city, Saudi Arabia. J Clin Exp Dent. 2016; 8(4): e379. Doi: 10.4317/jced.52811

5. Althomairy SA, Baseer MA, Assery M, Alsaffan AD. Knowledge and attitude of dental health professionals about Middle East respiratory syndrome in Saudi Arabia. J Int Soc Prev Community Dent. 2018; 8(2): $137 . \quad$ Doi: 10.4103/jispcd.JISPCD_9_18

6. Elrggal ME, Karami NA, Rafea B, Alahmadi L, Al Shehri A, Alamoudi $R$, et al. Evaluation of preparedness of healthcare student volunteers against Middle East respiratory syndrome coronavirus (MERS-CoV) in Makkah, Saudi Arabia: a cross-sectional study. Z GesundhWiss. 2018; 26(6): 607-12. Doi: 10.1007/s10389-018-0917-5

7. Kharma MY, Alalwani MS, Amer MF, Tarakji B, Aws G. Assessment of the awareness level of dental students toward Middle East Respiratory Syndromecoronavirus. J Int Soc Prev Community Dent. 2015; 5(3): 163. Doi: 10.4103/2231-0762.159951

8. Hoda J. Identification of information types and sources by the public for promoting awareness of Middle East respiratory syndrome coronavirus in Saudi Arabia. Health Educ Res. 2016; 31(1): 12-23. Doi: 10.1093/her/cyv061

9. Jeon $\mathrm{MH}, \mathrm{Kim} \mathrm{TH}$. Institutional preparedness to prevent future Middle East respiratory syndrome coronavirus-like outbreaks in Republic of Korea. Infect Chemother. 2016; 48(2): 75-80. Doi: 10.3947/ic.2016.48.2.75.

10. Perrella A, Carannante N, Berretta M, Rinaldi M, Maturo N, Rinaldi L. Editorial-Novel Coronavirus 2019 (Sars-CoV2): a global emergency that needs new approaches?. Eur Rev Med Pharmaco Sci. 2020; 24(4): 2162-4. Doi: 10.26355/eurrev_202002_20396

11. Del Rio C, Malani PN. 2019 Novel coronavirusimportant information for clinicians. JAMA. 2020 Doi:10.1001/jama.2020.1490.

12. World Health Organization. Coronavirus disease 2019 (COVID-19). 2020; Situation Report - 46. Accessed on 16th March 2020. 
13. Ministry of National Health Services, Regulations and Coordination. Daily Situation Report - Pakistan COVID-19. 2020. Accessed on 16th March 2020

14. Sabino-Silva R, Jardim AC, Siqueira WL. Coronavirus COVID-19 impacts to dentistry and potential salivary diagnosis. Clin Oral Investig. 2020. Doi: 10.1007/s00784-020-03248-x.

15. Omrani AS, Al-Tawfiq JA, Memish ZA. Middle East respiratory syndrome coronavirus (MERS-CoV): animal to human interaction. Pathog Glob Health. 2015; 109(8): 354-62. Doi: 10.1080/20477724.2015.1122852

16. Harrel SK, Molinari J. Aerosols and splatter in dentistry: a brief review of the literature and infection control implications. J Am Dent Assoc. 2004; 135(4): 429-37. Doi: 10.14219/ jada.archive.2004.0207

17. Corstjens PL, Abrams WR, Malamud D. Saliva and viral infections. Periodontol 2000. 2016; 70(1): 93110. Doi: $10.1111 /$ prd.12112.

18. Corstjens PL, Abrams WR, Malamud D. Detecting viruses by using salivary diagnostics. J Am Dent Assoc. 2012 ;143: 12S-8S. Doi: 10.14219/ jada.archive.2012.0338

19. Johnson NP, Mueller J. Updating the accounts: global mortality of the 1918-1920" Spanish" influenza pandemic. Bull Hist Med. 2002: 76(1): 105-15. Doi:10.1353/bhm.2002.0022

20. Andrewes $\mathrm{CH}$. Epidemiology of influenza. Bull World Health Organ. 1953;8(5-6):595.

21. Lina B. History of influenza pandemics. In Paleomicrobiology 2008 (pp. 199-211). Springer, Berlin, Heidelberg.

22. Bean A, Baker M, Stewart C, Cowled C, Deffrasnes C, Wang LF, et al. Studying immunity to zoonotic diseases in the natural host - keeping it real. Nat Rev Immunol. 2013; 13: 851-61. Doi: 10.1038/nri3551

23. Guan $Y$, Zheng BJ, He YQ, Liu XL, Zhuang ZX, Cheung $\mathrm{CL}$, et al. Isolation and characterization of viruses related to the SARS coronavirus from animals in southern China. Science. 2003 Oct 10;302(5643):276-8. DOI:10.1126/science.1087139

24. Bautista E, Chotpitayasunondh T, Gao Z, Harper SA, Shaw M, Uyeki TM, et al. Writing Committee of the WHO Consultation on Clinical Aspects of Pandemic (H1N1) 2009 Influenza. Clinical aspects of pandemic 2009 influenza A (H1N1) virus infection. N Engl J Med. 2010; 362(18): 1708-19. Doi: 10.1056/NEJMra1000449

25. Hsieh MC, Tsou TP, Chen WC, Kuo SH. The response to novel influenza A ( $\mathrm{H} 1 \mathrm{~N} 1$ ) epidemic in Taiwan and analysis of the initial 61 confirmed cases. Epidemiology Bulletin. 2009; 25(8): 556-67.
26. Oboho IK, Tomczyk SM, Al-Asmari AM, Banjar AA, AlMugti H, Aloraini MS, et al. 2014 MERS-CoV outbreak in Jeddah - a link to health care facilities. N Engl J Med. 2015 Feb 26;372(9):846-54. Doi: 10.1056/NEJMoa1408636.

27. Widjaja I, Wang C, van Haperen R, Gutiérrez-Álvarez J, van Dieren B, Okba NM, et al. Towards a solution to MERS: protective human monoclonal antibodies targeting different domains and functions of the MERS-coronavirus spike glycoprotein. Emerg Microbes Infec. 2019; 8(1): 516-30. Doi:10.1080/22221751.2019.1597644

28. Zhang J, Li Y, Jin Z, Zhu H. Dynamics Analysis of an Avian Influenza A (H7N9) Epidemic Model with Vaccination and Seasonality. Complexity. 2019; 2019: 4161287: 15. Doi.org/10.1155/2019/4161287

29. Munster VJ, Koopmans $M$, van Doremalen N, van Riel D, de Wit E. A novel coronavirus emerging in China-key questions for impact assessment. $\mathrm{N}$ Engl J Med. 2020; 382(8): 692-4. Doi: 10.1056/NEJMp2000929

30. Massachusetts General Hospital. COVID-19 Treatment Guidance. Version 1.0 3/17/2020

31. Slots J, Slots H. Bacterial and viral pathogens in saliva: disease relationship and infectious risk. Periodontol 2000. 2011; 55(1): 48-69. Doi: 10.1111/j.1600-0757.2010.00361.x

32. Corstjens PL, Abrams WR, Malamud D. Detecting viruses by using salivary diagnostics. J Am Dent Assoc. 2012; 143: 12S-8S. Doi: 10.14219/ jada.archive.2012.0338

33. Harte JA. Standard and transmission-based precautions: an update for dentistry. J Am Dent Assoc. 2010; 141(5): 572-81. Doi: 10.14219/ jada.archive.2010.0232

34. Samaranayake LP, Peiris M. Severe acute respiratory syndrome and dentistry: a retrospective view. J Am Dent Assoc. 2004; 135(9): 1292-302. Doi: 10.14219/jada.archive.2004.0405

35. Ashok N, Rodrigues JC, Azouni K, Darwish S, Abuderman A, Alkaabba AA, et al. Knowledge and Apprehension of Dental Patients about MERS-A Questionnaire Survey. Journal of clinical and diagnostic research: JCDR. 2016; 10(5): ZC58. Doi: 10.7860/JCDR/2016/17519.7790

36. Scully C, Kirby J. Statement on mouth cancer diagnosis and prevention. $\mathrm{Br}$ Dent J. 2014; 216(1): 37-8. Doi: 10.1038/sj.bdj.2013.1235

37. Smales FC, Samaryanka LP. Maintaining dental education and specialist dental care during an outbreak of new coronavirus infection. Part 1: A deadly viral epidemic begins. $\mathrm{Br}$ Dent J. 2003; 195(10):557-61. Doi:10/sj.bdj.4810723 
38. Ibrahim NK, Alwafi HA, Sangoof SO, Turkistani AK, Alattas BM. Cross-infection and infection control in dentistry: Knowledge, attitude and practice of patients attended dental clinics in King Abdulaziz University Hospital, Jeddah, Saudi Arabia. J Infect Public Health. 2017; 10(4): 438-45. Doi: 10.1016/j.jiph.2016.06.002
39. Al-Sehaibany FS. Middle East respiratory syndrome in children: Dental considerations. Saudi med J. 2017; 38(4): 339. Doi: 10.15537/smj.2017.4.15777

40. Monaghan NP. Emerging infections-implications for dental care. $\mathrm{Br}$ Dent J. 2016; 221(1):13. Doi: 10.1038/sj.bdj.2016.486. 